\section{Michigan Technological \\ 18 8 5 University}

Michigan Technological University Digital Commons @ Michigan Tech

Global Conference of the Youth Environmental Alliance in Higher Education

Dec 9th, 2:24 PM - 2:35 PM

\title{
Session 1D Green Imperialism in French Polynesia
}

Sara Mills

Follow this and additional works at: https://digitalcommons.mtu.edu/yeah-conference

\section{Recommended Citation}

Mills, Sara, "Session 1D Green Imperialism in French Polynesia" (2020). Global Conference of the Youth Environmental Alliance in Higher Education. 16.

https://doi.org/10.37099/mtu.dc.yeah-conference/2020/all-events/16 


\section{Avoiding "Green Imperialism": Examining the Relationship Between France and French Polynesia \\ Sara Mills}

\section{Background}

French Polynesia (FP) is a collection of 118 islands in the South Pacific and a former French colony (Vieux et al. 4)

-The islands are considered "autonomous" and not independent of

FP has a booming tourism industry and relies heavily on the sea for hydropower and fishing (Vieux et al. 9, Opeskin and MacDermott For 30 years, FP was the site of a French nuclear testing site, causing environmental and health problems for residents (Malogne-

Thertaining as to what FP's .

$$
\text { r. }
$$

\section{Policy Problems}

- Due to FP's position as a small island developing state (SIDS), the slands and their economy are particularly vulnerable to sea level - Victims of the effects of the

estorical nuclear imperialism in the

region have failed to receive compensation for their illnesses

(Malogne-Fer)

Prior to colonialization, society was organized into mobile small tribal groupings

- Colonialization has made migration more difficult, despite its necessity as an adaptation measure (Opeskin and

- Current adaptation measures rely on:

1. Integrated Coastal Management (ICM)

$$
\text { 12-13) }
$$

This allows French resource interests to continue in FP, while promoting sustainability.
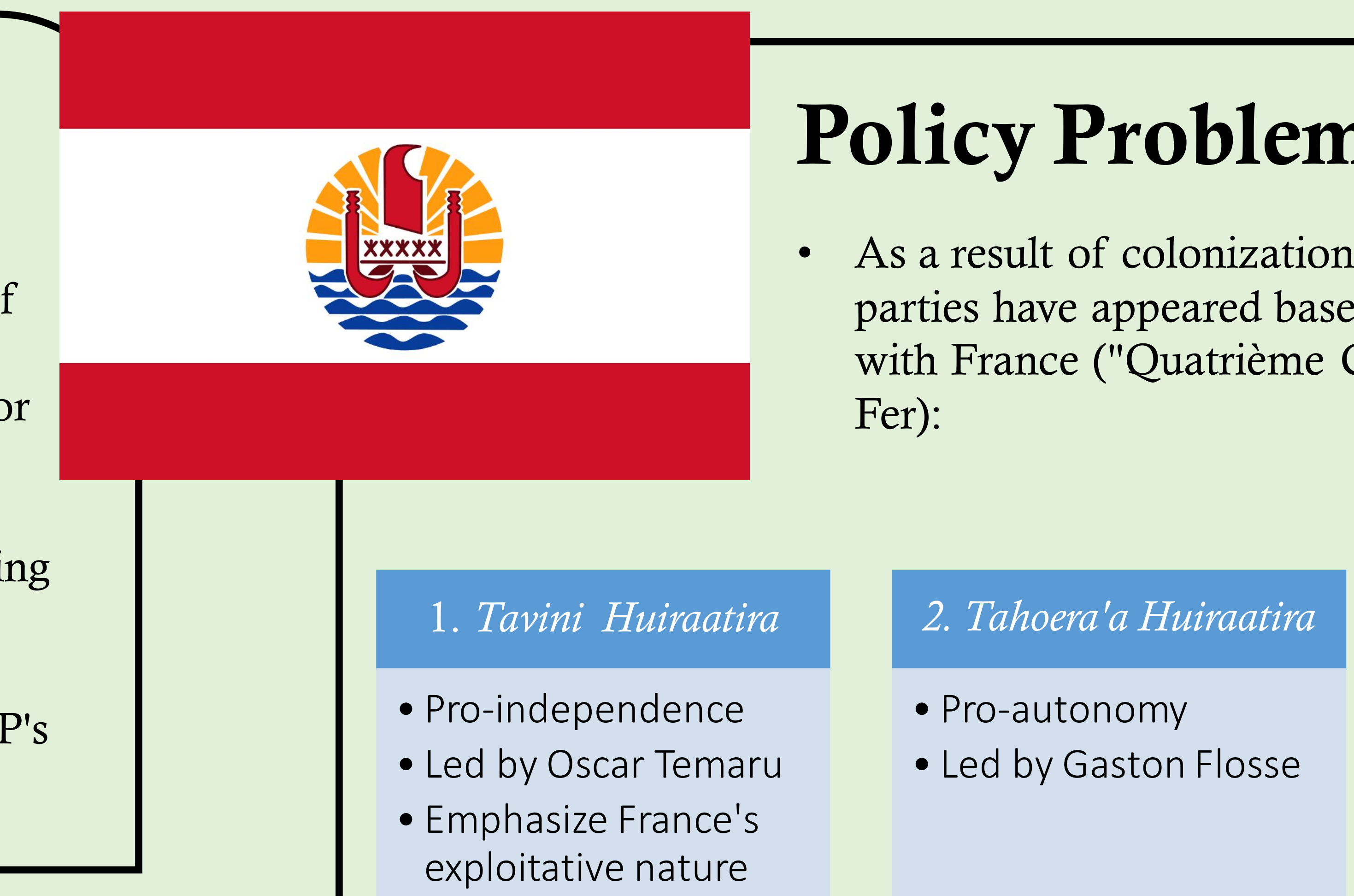

\section{Tapura Huiraativa \\ - Pro-autonomy \\ - Break off from
Flosse's party \\ - Led by President \\ Eduoard Fritch \\ - Emphasize France's \\ aid and development}

Historical French development projects in FP (Walker et al. 708):

1. Le Pacte de Progrès:

Introduced towards the end of the nuclear test site

period (1990s) agricultural development

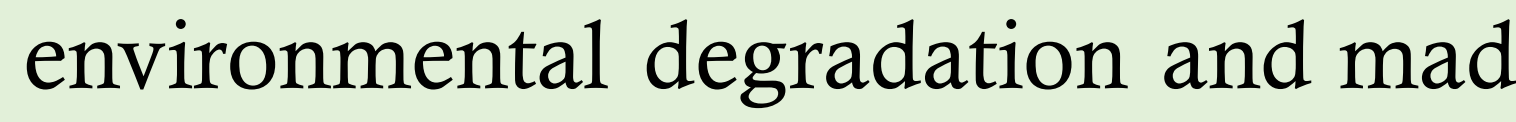
the FP economy dependent on few sectors, making more vulnerable to change.

10 RLIMATE

(U) ABTION

2. Plan de Gestion de l'Espace Maritime:

Mapped lagoon areas and restricted fishing for

environmental regulation purposes

Mapping and quantification failed to take into consideration indigenous spiritual meanings associated with natural resources

- There is a political/cultural divide between the FP's relationship with France, as well as environmental justice tensions based on their colonized past and nuclear imperialism Economically-focused development projects have been prioritized over environmentally sustainable ones

ainable development projects fail to address cultural perceptions of the environment and seek to maintain French economic interests in the region

Policy concerns regarding how France can promote sustainable development while also extracting resources and failing to provide compensation for victims of nuclear fallout

\section{Potential Solutions}

While sustainable development projects are not entirely negative, perspectives regarding France and FP's relationship must shift in order to void "green imperialism"

Developed countries using global environmental agenda to impede economic growth of developing countries (Scholtz 288) France currently exploits FP resources under the provision that the country has claim to them since FP is an entity of France

This reinforces the perspective of the "common heritage of mankind" (CHM) (273-275)

CHM was first proposed by Malta's representative to the UN in fear of technologically advanced countries being able to exploit resources from the sea as stronger competitors

Developing contries sought CHM to have a space in CHM, however, assures developed states' ideas of freedom regardin their right to resources, thus promoting resource exploitation for commercial gains.

An alternative to $\mathrm{CHM}$ is the "common concern of mankind"(CCM)

intenational law around "consequences", rather than "survival" through economic means (i.e., resource extraction) (283-284)

Draws focus away from the economic side to one of worry about climate change and its impacts

Fring to prevent the exploitation of resources. Spatial and

temporal contexts must also be considered to ensure the incorporation of local knowledge and attitudes about the well as compensate for past colonial injustices.

\section{References}

Hetea Ierorotua, etal al "Assessing Perception of Climate Change by Representatives of Public Authortities and Designing
Coastal Climate Services: Lessons Learnt From French Polynesia." Frontiers in Marine Science, vol. 7, Mar. 2020. EBSCOhost Pacific", Journal of Postcolonial Writing, vol. 54 , no. 5 , oct. 2018, pp. 585-600. EBSCOhosst

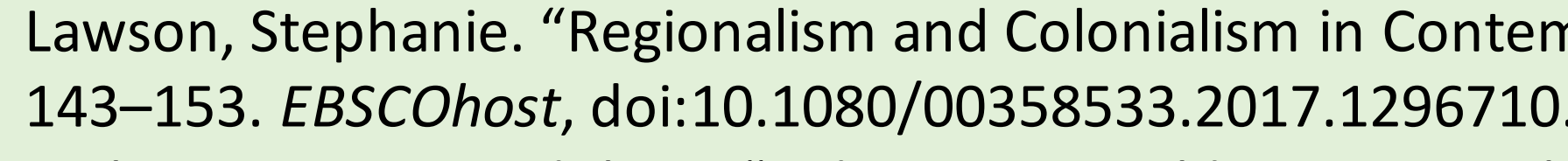

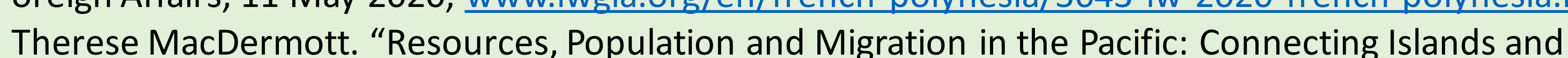

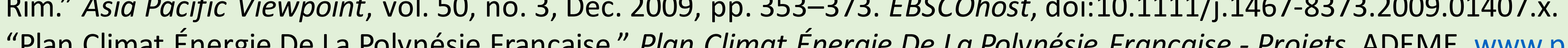

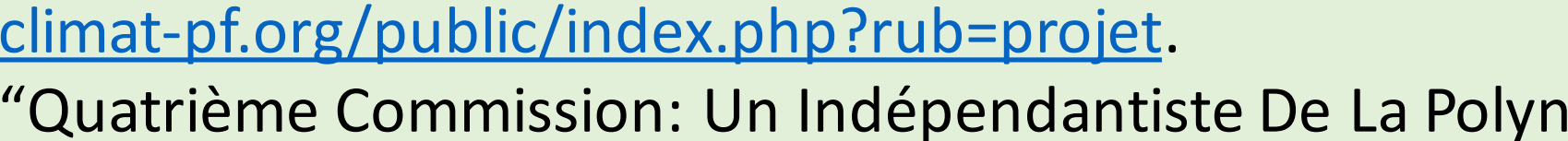
( Scholtz, Werner. "Common Heritage: Saving the Environment for Humankind or Exploiting Resources in the Name of Eco-

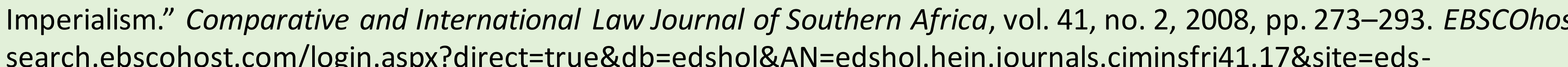
Vieux, Caroline, et al. “Action Plan: French Polynesia." Integre, Pacific Community, 2017,

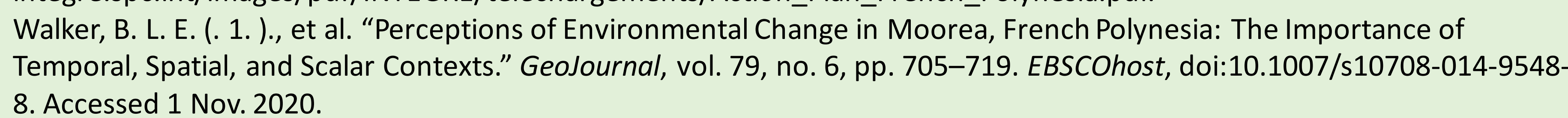

